\title{
Kill, incarcerate, or liberate? Ethics and alternatives to orangutan rehabilitation
}

\begin{abstract}
Despite its high cost and debatable conservation value, orangutan rehabilitation and reintroduction (R\&R) continues. Drawing on qualitative research with orangutan conservationists, this paper argues that a central reason why $R \& R$ practitioners undertake this activity is a view that the alternatives, killing orangutan orphans or keeping them in captivity, are practically or ethically unacceptable. However, questions remain over whether orphans might be better off in captivity than in the wild, and why orphans appear to attract more attention and support than wild orangutans. In evaluating these questions, practitioners must weigh up obligations to individuals and larger units, displaced and wild orangutans (the former visible, and the latter abstract), and properties of orangutans such as their wildness, welfare, and autonomy. As advocates of compassionate conservation have highlighted similar ethical dilemmas arise in the conservation of other species.
\end{abstract}

Keywords: rehabilitation, reintroduction, apes, orangutans, ethics, compassionate conservation

\section{Introduction}

Rehabilitation and reintroduction (R\&R) involves helping displaced or orphaned animals become healthy and socially and ecologically capable of surviving with greater independence, before release into the wild (Beck, Rodrigues, Unwin, Travis, \& Stoinski, 2007). With orangutans (Pongo spp.), R\&R first began in the 1960 , and today is undertaken at approximately $13 \mathrm{R} \& \mathrm{R}$ projects (Table 1 , upplementary material). R\&R may have conservation value-for example, as a tool for community education, facilitating forest protection, curbing illegal trade, and replenishing wild populations. However, these arguments are often challenged in the case of orangutan $\mathrm{R} \& \mathrm{R}$, particularly on the grounds that large viable populations remain in the wild, especially on Borneo (Utami Atmoko et al., 2017), and post-release survival is potentially poor (section 4). Furthermore, various benefits such as community education and providing a home for confiscated animals could as easily be achieved with sanctuaries providing lifelong care rather than R\&R (see Gipps, 1991; Lardoux-Gilloux, 1995; Rijksen and Meijaard, 1999; Rijksen, 2001; Russon, 2009; Trayford, 2013; Palmer, 2018, for reviews of orangutan R\&R, and 
Teleki, 2001; Cheyne, 2009; Beck, 2010, 2016, 2018; Trayford and Farmer, 2013; Guy, Curnoe, and Banks, 2014; Humle and Farmer, 2015 for other primates). R\&R costs approximately $\$ 44 \mathrm{k}$ per orangutan over an orangutan's lifetime (about 12 times as much as much as forest protection), and is therefore a less cost-effective long-term conservation strategy than habitat protection (Wilson, Meijaard, Venter, Ancrenaz, \& Possingham, 2014). For these reasons, attendees of a public discussion hosted by the World Land Trust in London in 2011 overwhelmingly rejected the motion that "[e]ven with limited funding available, reintroduction of captive orangutans is as important for their conservation as habitat protection."

Despite this apparent consensus that orangutan reintroduction is less important than other conservation activities, it shows no sign of slowing, with at least three new rehabilitation centers opening since 2015 (Table 1, Supplementary material), and perhaps a quarter (Meijaard, 2014), or even half (Wilson et al., 2014), of the annual Indonesian orangutan conservation budget going to R\&R (about US \$2om annually, with at least half coming from NGOs rather than the government: Meijaard, 2014). This paper examines why, regardless of its expense and debatable conservation value, orangutan R\&R will likely continue. Drawing on qualitative research with orangutan conservation practitioners, I argue that $\mathrm{R} \& \mathrm{R}$ is often undertaken primarily because it is viewed as the only acceptable option for dealing with orangutan orphans-the main alternatives being euthanasia or lifelong captivity. However, questions remain over whether orphans might be better off in captivity than in the wild, and why orphans appear to attract more attention and support than wild orangutans. This paper explores various perspectives held within the orangutan conservation community on whether there is an acceptable, or preferable, alternative to $R \& R$, and how to balance ethical obligations towards displaced and wild orangutans.

\section{Methods}

Research involved interviews with orangutan conservation and welfare practitioners, especially those involved in $\mathrm{R} \& \mathrm{R}$ and with some decision-making capacity, such as non-governmental organization (NGO) directors, R\&R project managers, donors, and researchers. In-depth interviews in person or over Skype/phone were conducted with 81 participants. A further three responded to questions by email, 10 participated in short interviews or other correspondence, and seven informally discussed information pertinent to the research. Interviews followed a semi-structured format, following a general structure but allowing flexibility to pursue unexpected topics as they arose. First participants were individuals known to be key players in orangutan conservation, such as NGO directors and researchers. Further participants were recruited opportunistically (e.g., while visiting projects), and through recommendations from other participants and "theoretical sampling": selecting participants for what they would likely contribute to the project, such as offering contrary views or new areas of expertise (Orne \& Bell, 2015, p. 69). Individ- 
uals with a significant public presence (e.g., NGO directors, many of whom appear in popular media such as documentaries) were informed that they would not be anonymized, though they could choose for specific comments to be anonymized or not included, and others (e.g., vets, field staff, donors) were offered the option of remaining anonymous. Anonymized comments are referenced as "anon." A list of the 65 named interviewees is included in the Supplementary material.

Research also involved participant-observation at events in the UK and Southeast Asia (e.g., a private fundraising meeting, meetings of practitioners, and public fundraising events and lectures). Between May and August, 2016, visits of 1-5 days were paid to orangutan conservation projects on Borneo and Sumatra, including six rehabilitation centers, three release sites, three orangutan tourism and research projects, and one NGO-owned forest. Arguments about orangutan R\&R were examined in both peer-reviewed literature and popular media (e.g., blogs, books, documentaries, and social media). This research was approved by the $\mathrm{X}$ Department of Anthropology Ethics and Fieldwork Committee and the Ministry of Research, Technology and Higher Education of the Republic of Indonesia (RISTEK, 173/SIP/FRP/E5/Dit.KI/V/2016).

\section{Euthanasia}

Even 16 individuals with substantial involvement in conducting, funding, studying, or otherwise supporting R\&R compared habitat protection favorably to R\&R in terms of cost-effectiveness or its ability to solve the underlying cause of orangutan endangerment. R\&R was acknowledged as a "band-aid on the problem" (Gail Campbell-Smith, 2016-06-07), much like "paracetamol" for the flu (Karmele Sanchez, 2016-06-09), or a "fire brigade [...] You're always better off preventing fires than you are fighting them" (Nigel Hicks, 2015-12-09). For 23 participants (20 of whom were substantially involved in R\&R), ethical obligations or a lack of suitable alternatives were central reasons for viewing $R \& R$ as worthwhile. As summarized by James Robins (2016-04-08), formerly director of the Tabin orangutan reintroduction project in Sabah, $R \& R$ is "clearly not as cost-effective as habitat protection $[\ldots]$ but that's not what motivates a lot of people working in the industry [...] I think, particularly from my point of view, what do we do with these animals, you know?" The seven participants involved in R\&R who placed greatest emphasis on its conservation value were involved in projects on Sumatra rather than Borneo (the difference between $\mathrm{R} \& \mathrm{R}$ on the two islands is beyond the scope of this paper).

There are two main alternatives to R\&R: killing orphaned orangutans, or keeping them in lifelong captivity (Harcourt, 1987; Beck, 2010; Moore, Wihermanto, \& Nekaris, 2014). "Dumping" orphaned orangutans into the wild without undergoing necessary rehabilitation could be considered ethically "pretty much the same as euthanasia" (Sanchez), since the purpose of rehabilitation is to assist orangutans that would otherwise have a slim chance of survival; however, it could also be viewed as comparable to releasing orangutans with minimal post-release support, 
which could be justified as giving orangutans "death with dignity" (section 4). In either case, although "dumping" represents a distinct management technique which is sometimes used for other species, such as gibbons (Palmer, 2018) - it involves similar ethical issues to euthanasia and R\&R. It is beyond the scope of this paper to discuss "dumping" in detail.

Euthanasia was widely endorsed for obviously suffering orangutans, such as those with serious diseases. The issue of disease containment was also brought up in relation to orangutans with tuberculosis, specifically at Samboja Lestari in East Kalimantan (Table 1, Supplementary material), which housed 44 orangutans with TB during my visit (Agus Irwanto, 2016-06-30). However, several practitioners, drawing on cases from two rehabilitation centers, indicated that government permission to euthanize even "deserving cases" (anon) in Indonesia is rarely granted (see also Rouxel, 2012). Four participants discussed the possibility that some groups may need to consider killing orangutans that cannot be released, even those that do not obviously suffer. This idea was proposed as a way of freeing up resources to spend on those that can be released, or because it might be "in the interest of the animal's wellbeing to kill it" rather than keep it in "inhumane" or overcrowded conditions in rescue centers for its whole life (Pokras, in comments on Lindburg, 1995, p. 169; see also Karesh, 1995; Moore et al., 2014). (Invoking similar logic, two participants argued that even orangutans with dubious survival skills would be better off if "given a chance" in the wild than left to suffer in a small cage.) Certainly, conditions in orangutan rehabilitation centers are generally poor, with many cages smaller than those recommended for laboratory-housed apes (Trayford, 2013, p. 111). One participant was open to the possibility of euthanizing all displaced orangutans, on the grounds that they are "biologically a dead end." However, the remaining participants voiced only objections to the idea of euthanizing healthy orangutan orphans.

Some objections to euthanasia were practical: not only is it currently illegal in Indonesia, and would not solve the underlying problem, but "the social backlash overseas would be enormous" (Graham Usher, 2016-07-156; similar point voiced by four others). Furthermore, in Indonesia and Malaysia "how are we going to stop people from killing orangutans if the government or the NGOs or general society in the world decides that this is the right thing to do? Forget about ever stopping the problem" (Sanchez; similar point made by one other). Ethical justifications were also frequently cited, most prominently the idea that "we have a moral responsibility to do something about these animals that we've displaced" (Graham Banes, 2016-02-17). This idea references notions of justice and fairness: we must "take responsibility" (Birute Galdikas, 2016-06-16), since "it's not their fault they've ended up in this horrific situation" (Susan Cheyne, 2015-10-26), and they therefore "deserve extra special treatment" (Robins; similar argument made by three more). The principle of righting humanity's wrongs does not necessarily entail viewing orangutans as possessing rights (e.g., to life, or to freedom), since its primary goal is atoning for guilt about our treatment of other species (Cribb, Gilbert, \& Tiffin, 2014, p. 5). However, several individuals involved in orangutan conservation and 
R\&R are known for their public support for great ape rights (e.g., Birute Galdikas, Gary Shapiro, Leif Cocks, Richard Zimmerman), and others explicitly voiced the idea that orangutans deserve "a right to life, and the right to not be impeded by human activity" (Michelle Desilets, 2015-11-03), or of "animals as people" (Signe Preuschoft, 2016-06-25). Such views were not only expressed by animal welfare or rights advocates but also by some self-described conservationists, such as Erik Meijaard ("an orangutan as a great ape has rights, a right to live that I value very highly": 2015-09-01) and Ian Singleton, who described orangutans as "people" (2016-07-12).

Five participants explicitly indicated that they care for all animals equally, or have particular affection for species less closely related to humans. Others objected to the prioritization of orangutans on the grounds that all animals equally deserve care (voiced by 3) or are equally important ecologically (2). On the other hand, three participants openly acknowledged that they find the welfare or life of great apes more important than for other animals. For example, zoologist Benjamin Beck proposed that the great apes' intelligence and rich emotional lives grant them "special consideration by humans" (2016-05-02; see Warren, 2001, for a similar argument). Yet an additional 11 indicated that they they felt, or now feel, a special connection with orangutans, largely derived from intimate contact, which prompted them to "fall in love" with orangutans (Jamartin Sihite, 2016-10-07), be "literally obsessed with these majestic creatures" (Richard Zimmerman, 201507-16), or "want to be part of their world" (Panut Hadisiswoyo, 2016-08-19). Eye contact was frequently referenced in such accounts, the primary reason being that orangutans appear "so human!" (Hadisiswoyo): "you see the soul behind the eyes. It's kind of like, 'There's something deep in there. This is a thinking, sensitive, sentient being if I ever saw one" (Desilets). Descriptions of eye contact with non-human great apes as "humbling" (Russon, quoted in Siegel, 2005, p. 201) or "shocking in its profoundness" (Galdikas, 1995, p. 403) occur regularly in accounts from researchers (see also Kortlandt, 1994, p. 141) and volunteers at rehabilitation centers (e.g., see Parreñas, 2012). Rose (1995) has labeled such accounts a form of Profound Interspecies Experience (PIE), specifically those in which humans "seek a friendly encounter (SAFE)" with an animal, especially large vertebrates. Thus, although open admissions of speciesism were rare, greater discomfort with killing orangutans than other species was often implied in how practitioners spoke about orangutans.

Another important consequence of PIEs is the emotional challenge of killing orphaned orangutans. For example, Sara Fell Hicks (2015-12-09), who alongside her husband provides veterinary assistance and supplies at orangutan $R \& R$ projects, described hearing a volunteer argue that "all the money needs to be going into forest protection" rather than $R \& R$, such that " $[w]$ e should be killing " orphaned orangutans. To this, Fell Hicks challenged the volunteer to do a vet's job: "I said to him, 'So you kill it! You euthanize it! Don't ask other people to do that. Would you do it yourself?' and he said, 'No,' and I said, 'Well, there you go. There's your answer.' Who is going to do that?" Thus, just as technicians in animal laboratories 
and veterinarians struggle with killing healthy animals (Arluke \& Sanders, 1996; Morris, 2012; Greenhough \& Roe, 2017), veterinarians at R\&R centers would be faced with a distressing task, which perhaps few external critics of R\&R would be willing to undertake themselves.

\section{Captivity}

Although killing orphaned orangutans was often dismissed, there was more debate about lifelong captivity as an acceptable alternative to R\&R. According to the IUCN (2000, pp. 2-3), reintroduction is risky and "generally confers few benefits," meaning that retaining animals in captivity is "a clear - and, in most cases, preferable alternative." Despite this advice, all NGOs that confiscate orangutans aim to release them back into the wild.

Some reasons for preferring reintroduction to captivity were once again practical, relating to housing supply. In-country zoos and rehabilitation centers generally have poor conditions (Karesh, 1995; Agoramoorthy, 2004; Nijman, 2009; Trayford, 2013). Karmele Sanchez was amenable to the idea that Indonesian zoos could house orphaned orangutans if standards dramatically improved, but viewed rapid improvement as unrealistic. Indeed, two organizations indicated that they have rescued animals from Indonesian zoos, and the Centre for Orangutan Protection (COP) for a time assisted with orangutan care at a zoo in Samarinda, but campaigned for the zoo's closure after it failed to improve its conditions (Paulinus Kristianto, 2016-06-25). Construction is considerably cheaper in most ape range countries than in the West, and sanctuaries could potentially earn income from tourism, but building and operating high-quality sanctuaries is still expensive (Beck, 2010). John Burton (2015-07-15) raised the idea that orphaned orangutans could be sent to overseas zoos, which could make space by ceasing captive breeding. Barbara Harrisson (1962) sent orphaned orangutans to overseas zoos before she founded the first orangutan R\&R project (Sepilok, Sabah) in 1964, so this move would be precedented.

However, two participants objected that in-country sanctuaries could educationally have a "massive impact in these countries where the animals actually live and come from" (Kay Farmer, 2016-01-12). Four also worried that sending orphaned orangutans overseas might act as "a way of legalizing getting around CITES" (Cheyne) by creating a legal route for transferring wild orangutans to international zoos. Currently this activity is prevented by cITEs because wild capture undermines orangutan conservation and violates Indonesian law (CITES, 1983). Maintaining genetic diversity is difficult in captive populations (Lees \& Wilcken, 2009), especially in orangutans since $12 \%$ of those recorded in the zoo studbook are Sumatran-Bornean hybrids, which are deemed surplus for breeding purposes (Elder, 2016). Zoos might therefore be "happy as clams to automatically get a whole bunch of orangutans that are ex-captives" (Anne Russon, 2015-10-16), leading to the possibility that rehabilitation centers would be used as clearing houses for selling 
wild-caught apes to zoos. On the other hand, researcher Graham Banes - whose recent work has involved helping zoos in developing countries with orangutan housing, husbandry, and breeding (Banes, Chua, Elder, \& Kao, 2018) - argued that transferring just the unreleasable orphaned orangutans to zoos in developing countries could help curb rather than exacerbate trade, since "if they [zoos in developing countries] want them, they'll get them." The individual orangutans would also benefit, since they would experience a "much higher quality of life" in a refurbished zoo in a developing country than in a small cage in a rehabilitation center. According to Banes, one reason his proposal has been unpopular is the idea that "you should never take animals from range countries and put them anywhere else." To this, Banes argued, "But we define what a range country is-orangutans don't care about geopolitical borders, all they care about is their conditions, their life, their standard of living." Discussions of housing for orangutan orphans might therefore in part reflect ideas about whether wildlife "belong" to states, which Meijaard (2015) argues is expressed when the Indonesian public occasionally demands that overseas zoos return "our" orangutans. At a provincial level, the government of Aceh, Sumatra, demanded that all orphaned orangutan confiscated in the province must be reintroduced in Aceh (Singleton, 2011). Another participant proposed that government representatives may sometimes feel entitled to see or hold orangutans at $\mathrm{R} \& \mathrm{R}$ projects, since " $[\mathrm{t}]]$ he orangutans are property of the state, [and] I am state official." Challenging the notion of national ownership, Erik Meijaard (2015) argues that although orangutans and all other natural resources are "under the powers" of the Indonesian state, one could interpret "under the powers" to imply "management authority" rather than ownership, meaning that orangutans are better seen as "common goods" over whom "the whole world has some say." A more practical issue is that the number of orangutans in rehabilitation centers $(\sim 1,250$ : Table 1 , Supplementary material) may exceed the number in zoos, with 1106 recorded in 2015 (Elder, 2016), though many institutions do not report to the studbook (Beastall, Bouhuys, \& Ezekiel, 2016). Many of these orangutans are housed in zoos in developing countries, particularly in the Asian region, which face greater challenges to sound management than zoos in the developed world (Banes et al., 2018). Currently $57 \%$ of orangutans recorded in the studbook reside in zoos in Europe, North America, and Australasia.

Ethical reasons were also central to arguments for and against captivity. A key question is whether, from the individual orangutan's perspective, captivity is preferable to release into the wild. Over 2100 orangutans have probably been released since the 1960s (Tables 2-3, Supplementary material). Few past orangutan $\mathrm{R} \& \mathrm{R}$ projects conducted post-release monitoring, and those that did may not have reported their results, or employed variable (and not always specified) definitions of "success" (e.g., some counted orangutans lost to trackers as "successful": Russon, 2009). The few available reports claim a success rate of between $20 \%$ and $80 \%$, which is "as mixed as it is for other primates, not the best, but also not the worst" (Russon, 2009, p. 335). In some cases survival is thought to have been particularly poor, such as Sungai Wain where records from four years of tracking suggest 
survival of $20-45 \%$ (Rijksen \& Meijaard, 1999; Russon, 2009), and Meratus where only 16-18 orangutans of the 345 released between 1997 and 2002 were sighted in 2009 (Siregar, 2010). One could therefore argue that "in the mind of a Hominoid the conditions of regular provisioning and care in captivity are usually more favourable than 'freedom' and the prospect of independency in a largely unknown and possible hostile forest" (Rijksen \& Meijaard, 1999, p. 152). Reintroduced animals in general may face "displacement by others with established territories, injury from predators, debilitation from malnutrition, and eventual death, thus raising welfare questions" (Karesh, 1995, p. 3). For this reason, the Association of Zoos and Aquariums (1992) recommends that "[i]n view of the considerable mortality inherent in even the best planned and managed reintroduction programs, the reintroduction of orphans should not be represented as 'humanitarian' "(see also Karesh, 1995; Swaisgood, 2010; Harrington et al., 2013). Some, including Jane Goodall (2001, p. xx), have even wondered if wild apes might be better off in captivity, given how hard humans make their lives in the wild (see also Braverman, 2012; Palmer, Malone, and Park, 2016). Thus, Benjamin Beck concluded that because there is "little prospect or need" for ape R\&R from a conservation perspective, and "[a] good life in captivity is OK," R\&R is not "morally or ethically essential" and lifetime care in high-quality sanctuaries would be a good alternative (see also Beck, 2010).

But Birkett and McGrew (2013) argue that even high-quality captivity provides inferior conditions than the wild for any apes that could be released. The authors point to the prevalence of "abnormal behaviors" among captive apes: behaviors performed exclusively or with much greater frequency in captive environments - such as self-harm, ingestion of feces or vomit, and stereotypic (repetitive, apparently purposeless) behaviors - which tend to signal poor welfare (see Brüne, Brüne-Cohrs, McGrew, and Preuschoft, 2006; Fam, Tan, and Waitt, 2012; Birkett and McGrew, 2013; Palmer, 2018, for reviews). Abnormal behaviors are even common in "good zoos," with chimpanzees at accredited zoos in the UK and US displaying coprophagy, hair plucking, stereotypies, and self-injury (McComb, 2009; Birkett \& Newton-Fisher, 2011). On these grounds, Birkett and McGrew argue that "all captive environments are problematic" for apes, and that "the only defensible reason for [keeping apes in captivity] is to offer lifelong sanctuary to those who cannot be returned to nature" (p.142). Leif Cocks (2015-09-15) - former zoo keeper and curator at Perth Zoo, and now director of NGO The Orangutan Project - similarly proposed that although it is "not that keeping all animals in zoos is some horrific thing" (giraffes, for example, would probably find a good-quality zoo "a lot better" than life in the wild), for "sentient, self-aware" animals such as elephants and great apes "it's not appropriate." Cocks's view that the zoo is a "prison" for orangutans motivated his decision to begin releasing Perth Zoo orangutans into Bukit Tigapuluh National Park, Sumatra, as part of the Frankfurt Zoological Society reintroduction program. To date, three orangutans have been released, with one lost to trackers, one currently being tracked, and one dead from a snake bite (Cocks \& Bullo, 2008; Bullo, 2015; Perth Zoo, 2016). 
Cocks views freedom as crucial for orangutans' welfare. For others, freedom, or wildness, was important in itself. From a rights perspective, Femke den Haas (2016-10-10) of Jakarta Animal Aid argued that all animals have a "universal right to freedom." One participant, a former zookeeper, spoke of how incarcerated people and animals "lose[] something of themselves" (anon). Others have similarly argued that animals have greater "integrity" (Rijksen \& Meijaard, 1999, p. 162) in the wild, while a captive primate is a "shadow of themselves" (тор, 2016), a "very poor relation to the species in the wild" (Ashley Leiman in Doron, 2015), not a "real" primate but a "mere caricature molded by human contact" (Teleki, 2001, p. 135), or comparable to a human in "prison or in a mental institution" (Harrisson, 1962, p. 73). The view that wildness is inherently good can be supported from a conservation perspective - in which rare, native, and wild animals are viewed as more valuable than abundant, non-native, and captive animals (Callicott, 1980; Aitken, 2004) - and an animal rights stance, which generally opposes captive institutions on the grounds that animals should "never [...] be treated as if they exist as resources for others" (Regan, 1983 [2004], p. xvii). Even some proponents of animal welfare argue that wildness, or freedom, outweighs concerns about wild animals' wellbeing, and thereby prefer not to interfere in the lives of wild animals. For example, Bekoff (in comments on Jamieson, 1995, p. 47) argues that although "it is too bad that deer get killed by wolves" and he "would perhaps like the world to be different," "there is a sense of wildness that is beautiful, that we should respect and admire" (see also Beausoleil, 2014).

Some spoke of a need to reintroduce orangutans for the sake of restoring the world to its rightful state. Two Indonesian participants spoke of orangutans "belonging" to the forest, an idea which researcher Sri Suci Utami Atmoko (201610-04) tied to Islam: orangutans "belong to the forest garden, so they should do their duty there," since "[a]ll God's creations - including animals and plants - are for us, for humans, for the good, and they have their own path themselves. For example, with the orangutans or with the other wildlife, why should they be in the forest? Because the forest needs them, and not in our garden..." This argument may be related to the Qur'an's emphasis on "balance' (mizan)," which was perhaps originally intended to discourage destruction of enemies' plants and livestock, but can be applied analogously to biodiversity conservation (Foltz, 2014, pp. 36-7). Christian theology was also invoked to advocate for restoring nature's balance, with CEO of the Borneo Orangutan Survival Foundation (BOSF), Jamartin Sihite, arguing that God put orangutans in the forest for a reason, rendering pet-keeping hubristic: "are you God?" (see Binde, 2001, for Roman Catholic conservation traditions). Referring instead to indigenous rights, Paulinus Kristianto (2016-o625), manager of the cop rehabilitation center, illustrated his perception of the goal of orangutan rehabilitation by drawing a circle, the start and end of which represented the wild: his goal is to restore the world to its natural order. Kristianto advocated for restoring nature's balance to ensure that indigenous Dayak people like himself can continue to use and live alongside the forest. This idea resembles instrumentalist conservation views in which nature is preserved for the benefit 
of people (Norton, 1982), as with "new" conservation approaches (e.g., see Soulé, 2013; Marvier, 2014).

The view that "wildness," or "freedom," is more important than welfare can lead to the idea that it is better to have "death with dignity in the wild than survival in captivity" (Seal, 1991, p. 44). Citing this argument, three participants proposed that unless an orangutan will likely disturb humans, such as by approaching villages, they should be given "a fighting chance; if they make it, they did, if they don't, at least they died with dignity, so to speak" (Carel van Schaik, 2017-03-08). Thus, while for some practitioners rehabilitation is intended to "make orangutan[s'] life good, to make orangutan survive in the forest. For us, it's not" (Kristianto). Interestingly, Utami Atmoko suggested that views about the acceptability of "death with dignity" often follow ethnic lines, with Western supporters' requests sometimes being "not in our way. Like, for example, especially with the animal welfare thing. For example, maybe for them it is unreleasable, but for us, 'Oh yes, why not give them a try-at least they can die in nature!' " A similar proposal was made by one Western practitioner. If true, this would suggest that Western practitioners place a greater emphasis on animal welfare than wildness, while Indonesian and Malaysian practitioners value wildness more than welfare.

Taken to an extreme, the notion that R\&R should be conducted for restoring the natural world rather than for orangutans' welfare could imply little need for post-release monitoring-a stance advocated by just one participant. However, amidst calls for more thorough monitoring (Beck et al., 2007) and developments in tracking technology (Trayford \& Farmer, 2012), many groups now monitor released orangutans, though the intensity of monitoring varies. For example, BosF conducts intensive monitoring for the first three months after release, which appear critical for re-adjustment to the wild (Husson et al., 2016), reduced monitoring for a further three months, and "semi-monitoring" until two years after release (Sihite). In contrast, intensive monitoring of orangutans released into Tabin (11 as of May 2016: OAUK, 2016) has continued since 2010 (Robins). Such discrepancies reflect differences in resources and the number in need of monitoring (e.g., James Robins described the intensive monitoring at Tabin as a "luxury" resulting from stable funding and few released orangutans), and ethical priorities, with some taking very seriously the idea that "we are responsible for keeping this animal alive" (Campbell-Smith) and should try to avoid "releasing these orangutans without the care and support they deserve" (Cocks). On the other hand, one could argue that while it is important to be "as efficient as you can, i.e. get as high a survival as you can," it may be more cost-effective from a conservation perspective to invest in other activities, given the high cost of monitoring (Usher). Utami Atmoko added that raising funds for post-release monitoring is "really difficult" because many donors "don't care." Another participant supplied a possible reason for this lack of interest: while one can do a "nice fundraising story where you open the cage and it runs out [...it's] no good for fundraising if they follow this animal and it dies." Documentary films, for example, often include emotive music at the moment the cage door is opened, accompanied by statements from narrators or staff about 
how "moving", "indescribable" (OAUK, 2016), "beautiful" (BBC Earth, 2012b) or "wonderful" it is to finally "[give] back the freedom that humans have taken from them" (BBC Earth, 2012a): "final, total freedom" (Tokiomate, 2015). Researcher Kay Farmer has labeled such depictions examples of "Free Willy Syndrome." In addition to potentially implying to the public and donors that release is the the end of the process, Free Willy Syndrome might also allow practitioners to overestimate survival, since "not knowing allows them to have hope, and that is what keeps them fighting" (Hannah Trayford, 2016-02-26). Survival estimates may therefore be especially high where negligible data are available. For example, Birute Galdikas (2016-06-22) estimates that 80-90\% of reintroductions around Camp Leakey were successful (Table 3, Supplementary material), but there are few published data beyond anecdotes, and the little data available paint a less hopeful picture (Yeager, 1997; Beck, 2018).

An intermediate option between captivity and reintroduction could be to maintain orangutans in a provisioned, free-ranging state throughout their lives. For example, BOSF has purchased an island that will eventually house unreleasable orangutans (BOSF, 2017). Hypothetically, all healthy orphaned orangutans could be housed in sanctuaries of this sort, which minimize the use of cages but may substantially restrict ranging. An alternative could be to release orangutans into a large forest but continue feeding them for as long as they require, such as via feeding platforms: locations where food is made available at designated times. This approach is employed at $\mathrm{R} \& \mathrm{R}$ projects that are open to large-scale tourism, namely the Malaysian rehabilitation centers and Tanjung Puting National Park (see supplementary materials). Feeding platforms were previously employed at Bukit Lawang, but ceased in 2015 (BukitLawang.com, 2017). There is some dispute about whether these tourism sites can truly be called $R \& R$ projects, or whether they are better described as zoos or sanctuaries (Palmer, 2018). At such projects, generations of orangutans may remain attracted to humans and dependent on provisioning (Yeager, 1997; Dellatore, Waitt, \& Foitovà, 2014; Russon \& Susilo, 2014). This option would therefore not satisfy those who prioritize wildness. Concerns have also been raised about orangutan health at such sites given the risks of receiving unhealthy food from tourists, contracting human illnesses, and other issues such as high infant mortality and cross-species violence (Muehlenbein et al., 2010; Nury, 2011; Kuze et al., 2012; Dellatore et al., 2014; Russon \& Susilo, 2014). One could instead offer feeding platforms but restrict tourism (as occurs, for example, at the Orangutan Foundation UK reintroduction site in Lamandau: see Supplementary materials), but is is unclear whether this strategy reduces mortality compared with other approaches to post-release support, such as targeted feeding.

\section{A disproportion in how much we care?}

While participants often argued that there is an ethical imperative to do something - be that R\&R or sanctuary care - with displaced orangutans, some raised the 
idea that R\&R might undermine the conservation of wild orangutans, thereby challenging the ethical argument for R\&R. One justification for this view is the idea that by rescuing orangutans (both orphans and those in conflict zones), orangutan conservation NGOs signal to companies and authorities responsible for habitat destruction that there is a solution for displaced wildlife. 22 participants raised concern about this issue, three of whom specifically criticized cases of NGOs accepting money for rescues. Janitorial metaphors were used to convey this concern: rescue teams are perceived as "the sweeping guy: orangutan sweeping team" (anon), "hoovering up the problems" (Meijaard), or as toilet paper for deforestation industries (Kristianto; see also Meijaard, 2017). However, three others countered that deforestation would probably occur irrespective of NGO rescues, or argued the large number of orangutans in R\&R centers are a source of "embarrassment" for authorities (anon) and prevent denial of the existence of human-wildlife conflict (Leo Biddle, 2016-02-22).

Other arguments proposing that R\&R undermines wild orangutan conservation focus on the disproportionate funding received by R\&R compared with other orangutan conservation activities, leading two participants to argue that we are "wasting our money to keep orangutans in rehabilitation" when preventionfocused activities are under-funded (Darmawan Liswanto 2016-06-16), or that it "does not make rational, scientific sense" to spend millions each year on rescue centers (Burton; see also MacKinnon and MacKinnon, 1991). Three others argued that while they see the purpose of R\&R, such as the need to fulfill our "moral responsibility" to displaced orangutans, it is "a bit misguided" to weight funding so heavily in favor of R\&R, such that we should "redirect much more" to wild populations (anon).

Yet 20 participants questioned whether much funding for R\&R could realistically be redirected to more cost-effective conservation activities, since R\&R and activities like habitat protection tend to be funded by different donors, with distinct motivations. A further five argued that irrespective of the degree of overlap, funding competition is not a serious issue. Available records indicate that R\&R is funded by a range of sources. For example, donations from the general public make up approximately $59-65 \%$ of income for Orangutan Foundation International, and the majority of supporting foundations were established by individuals or families (2014; 2015). However, it has also received support from National Geographic (OFI, 2014), and was a recipient of the USAID-backed Orangutan Conservation Services Program (Fisher, 2010). Similarly, although $52 \%$ of income for International Animal Rescue - an umbrella group that funds orangutan $R \& R$ and other animal welfare projects - came from the general public (excluding legacies: 2013), its subsidiary Yayasan IAR Indonesia generally uses IAR funds to operate its rehabilitation center, and grants (e.g., from Arcus: Arcus Foundation, 2017) to fund its other conservation activities (e.g., community outreach: Campbell-Smith). This example offers some support for the idea, expressed by 11 participants, that R\&R tends to be funded by the general public, and more obviously conservation-oriented activities by larger donors such as foundations and governments. Ian Singleton proposed that this 
is because large donors "want to see their money see real changes," such that if they give to $R \& R$ it tends to be for conservation-oriented elements such as release site acquisition. Unfortunately, it is difficult to give a more detailed picture of $R \& R$ funding, since few groups publish reports that enable such analyses. For example, although BOSF $(2016,2017)$ reports its donors and total income, it is unclear how much each donor contributed. Donation analysis is further complicated by the fact that many small foreign NGOs raise funds largely from the general public (e.g. USbased Orangutan Outreach), but they are listed as "foundations" in R\&R operators' funding records. Thus, it appears that although there is some overlap between donors of R\&R and other conservation activities, the extent of the crossover is unclear.

Participants also often argued that donors who support R\&R are "probably a lot more emotional, they're probably a lot more reactive" than those who give to habitat conservation (Robins), so in the absence of orangutan R\&R supporters would probably "go off and adopt a panda instead" (anon), or fund "a chimp sanctuary" (Helen Buckland, 2015-08-04) or "stray dogs [...], or old cats" (van Schaik). No research has investigated motivational differences between supporters of wildlife rehabilitation and traditional habitat conservation, though some broadscale studies have examined correlates (e.g., gender, age, education) of donation to different causes, including animal welfare and conservation (see Neumayr \& Handy, 2017, for review). For example, one UK study found that although conservation had a relatively even gender balance ( 1.2 female donors for every man), animal welfare was the most gender-biased of any cause, with 1.7 women donating for every man (Piper \& Schnepf, 2008). However, it is unclear whether such studies classify orangutan R\&R NGOs (if they were even included) as conservation or animal welfare groups.

Despite the lack of clarity, many participants proposed that conflict between $\mathrm{R} \& \mathrm{R}$ and other conservation activities is minimal. 39 participants spoke about how rehabilitant orangutans readily attract public attention and support, with 20 specifically arguing that fundraising for rehabilitation is easier than for other conservation activities. A common reason for this view was that rehabilitants' stories are "so much more captivating and more appealing to the public than a more nuanced, complicated story of habitat loss and degradation and fragmentation" (Mark Harrison, 2015-10-29). Thus, the public will gladly "adopt" infant orangutans but less willingly give to causes like forest restoration (Hadisiswoyo) or fire prevention (Zimmerman). For some, the appeal of rehabilitants is inevitable: as in humanitarian campaigns, "when you have massive carnage, people's minds just glaze over: they just can't fathom the kind of pain and suffering going on by the masses, but we can identify with an individual" (Gary Shapiro, 2015-08-15). This proposal reflects the idea that a desire to help the environment is usually motivated by emotional connections to individual animals, such as through "SAFE PIEs" (section 4; see also Hargrove, 1992; Aitken, 2004). However, others argued that it is "our fault that they like these images [of cute babies], because we provide these images, so we are actually driving the [demand]" (Sanchez). If true, this 
would suggest that if $R \& R$ receives an unfair proportion of attention, it is only because R\&R practitioners have "found a better way to sell their product; you didn't. A forest is not sexy? Shame on you-you didn't find a way to make the forest sexy enough" (Douglas Cress, 2015-08-25). The extent to which practitioners might modify the preferences of donors through campaign strategy is unclear.

A central issue is therefore a perceived "disproportion [in] how much we care" about wild and rehabilitant orangutans (anon). Thus, in response to my explanation that many feel an ethical imperative to undertake R\&R, a conservationist asked, "why aren't you fighting more vigorously against the genocide that's happening anyway with the land clearing and the conversion of the habitat?" (one researcher expressed a similar response). Similarly, Erik Meijaard argued that because " $[t]$ hey're all orangutans, whether they're in a cage or whether they're in the forest," it is better to consider "what is the best system to maximize the overall welfare of all the orangutans?" rather than think only of displaced individuals.

\section{Conclusion}

As this paper has illustrated, many practitioners who undertake R\&R feel an obligation to help displaced orangutans, despite knowing that from a conservation perspective their efforts would be better directed towards wild populations. The issue is perhaps ultimately that it is hard to "turn away from a small infant who looks at you with eyes filled with pain and hopelessness" (Goodall, 2001, p. xxviii). Known animals therefore receive more attention than hypothetical animals one has not met. Some argue that this is the right thing to do: Callicott (1992) suggests that just as it is unethical to care for your neighbor's children more than your own, so too is it wrong to neglect animals in your care (see also Rowan, in comments on Jamieson, 1995, p. 42; Norton, 1995). Responding to the needs of orphaned animals aligns with the "individualistic" approaches of animal welfare and animal rights, which at times conflict with the more "holistic" approach of conservation (Callicott, 1992; Warren, 1992). For example, animals may be killed, or have their welfare compromised, in the name of conservation, such as when introduced or extremely abundant species are thought to threaten ecosystem health (Aitken, 2004; Vucetich \& Nelson, 2007; Paquet \& Darimont, 2010; Ramp, 2013; Beausoleil, 2014; Ben-Ami et al., 2014). As a way of reconciling this conflict, "compassionate conservation" aims to introduce considerations for individuals into conservation decision-making (Aitken, 2004; Bekoff, 2013; Beausoleil, 2014; Moore et al., 2014; Ramp \& Bekoff, 2015).

But what exactly would a compassionate conservation approach look like for orangutans? As we have seen, practitioners disagree on whether displaced orangutans are better off in a hostile forest or a cage, such that even those who prioritize welfare disagree on the best course of action. Compassionate conservation approaches can even be used to justify killing animals in overcrowded rescue centers (Moore et al., 2014). And if orangutan $R \& R$ does indeed detract 
from the conservation of wild populations, as a few participants argued (section 5), perhaps the most compassionate approach could be to abandon rehabilitants in favor of habitat preservation. In short, even if everyone involved acknowledges the importance of both conservation and animal welfare (and perhaps even rights), they may continue to disagree on what to do with orphaned orangutans.

It is also worth noting that a central source of debate about orangutan $R \& R$ relates to methods rather than whether it ought to be done in principle. As pointed out by Herman Rijksen (2001, p. 68), founder of the Ketambe orangutan rehabilitation center in 1971 (Table 3, Supplementary material), the real dispute about R\&R has always been about methods, such as the presence of tourism at R\&R centers, which represents a "corruption of the concept of ape rehabilitation." Even among projects closed to the public there is substantial debate about methods, such as how to achieve independence from humans while providing sufficient emotional and social support for infants, and whether (and how) to provision released orangutans (see Palmer, 2018). Indeed, if post-release success rates, which "are commonly considered unsatisfactory" (Russon, Smith, \& Adams, 2016), could be improved through better methods, the case for $\mathrm{R} \& \mathrm{R}$ would be much more compelling.

The issues involved in deciding how best to help orangutans are therefore complex, and reflect not only practical constraints (e.g., a lack of suitable housing for orphaned orangutans) but also ethical priorities. In particular, practitioners must decide how to prioritize individuals and larger units, displaced and wild orangutans (the former visible, and the latter abstract), and properties of orangutans such as their wildness, welfare, and autonomy. Given the complexity of these issues, it is perhaps unsurprising that there is ongoing debate about the best course of action.

\section{References}

Agoramoorthy, G. (2004). Ethics and welfare in Southeast Asian zoos. fournal of Applied Animal Welfare Science, 7(3), 189-95.

Aitken, G. (2004). A new approach to conservation: The importance of the individual through wildlife rehabilitation. Aldershot, UK: Ashgate Publishing Limited.

Arcus Foundation. (2017). Grantees. Retrieved March 27, 2017, from http://www. arcusfoundation.org/grantees/

Arluke, A. \& Sanders, C. (1996). Regarding animals. Philadelphia, PA: Temple University Press.

Association of Zoos and Aquariums. (1992). Guidelines for reintroduction of animals born and held in captivity. Silver Spring, MD: Association of Zoos and Aquariums.

Banes, G. L., Chua, W., Elder, M., \& Kao, J. (2018). Orang-utans Pongo spp in Asian zoos: Current status, challenges and progress towards long-term population sustainability. International Zoo Yearbook, o(o). 
BBC Earth. (2012a). Free again: Orangutan diary. 22nd October. Retrieved June 26, 2017, from https://www.youtube.com/watch?v=vjAvg9Pgzuw

BBC Earth. (2012b). Released into the wild: Orangutan diary. 19th August. Retrieved June 26, 2017, from https://www.youtube.com/watch?v=QJU37j9MTSo

Beastall, C. A., Bouhuys, J., \& Ezekiel, A. (2016). Apes in demand for zoos and wildlife attractions in Peninsular Malaysia and Thailand. Selangor, Malaysia: TRAFFIC Southeast Asia. Retrieved from http://www.traffic.org/publications/apes-indemand-for-zoos-and-wildlife-attractions-in-peninsul.html

Beausoleil, N. J. (2014). Balancing the need for conservation and the welfare of individual animals. In M. C. Appleby, D. M. Weary, \& P. Sandøe (Eds.), Dilemmas in animal welfare (pp. 124-47). Boston, MA: Centre for Agriculture and Biosciences International (CABI).

Beck, B. B. (2010). Chimpanzee orphans: Sanctuaries, reintroduction, and cognition. In E. V. Lonsdorf, S. R. Ross, \& T. Matsuzawa (Eds.), The mind of the chimpanzee (pp. 332-47). Chicago, IL: University of Chicago Press.

Beck, B. B. (2016). The role of translocation in primate conservation. In S. A. Wich \& A. J. Marshall (Eds.), An introduction to primate conservation (pp. 241-56). Oxford: Oxford University Press.

Beck, B. B. (2018). A history of primate reintroduction. Retrieved November 2, 2017 , from http://www.drbenjaminbeck.com/the-history.html

Beck, B. B., Rodrigues, M., Unwin, S., Travis, D., \& Stoinski, T. (2007). Best practice guidelines for the re-introduction of great apes (E. A. Williamson, Ed.). Gland, Switzerland: IUCN/ssc Primate Specialist Group. Retrieved from http://www. primate-sg.org/best_practice_reintroduction

Bekoff, M. (2013). Ignoring nature no more: The case for compassionate conservation. Chicago, IL: University of Chicago Press.

Ben-Ami, D., Boom, K., Boronyak, L., Townend, C., Ramp, D., Croft, D. B., \& Bekoff, M. (2014). The welfare ethics of the commercial killing of free-ranging kangaroos: An evaluation of the benefits and costs of the industry. Animal Welfare, 23(1), 1-10.

Binde, P. (2001). Nature in Roman Catholic tradition. Anthropological Quarterly, $74(1), 15^{-27}$.

Birkett, L. P. \& McGrew, W. C. (2013). "Unnatural behavior": Obstacle or insight at the species interface? In R. Corbey \& A. Lanjouw (Eds.), The politics of species: Reshaping our relationships with other animals (pp. 141-55). Cambridge: Cambridge University Press.

Birkett, L. P. \& Newton-Fisher, N. E. (2011). How abnormal is the behaviour of captive, zoo-living chimpanzees? Public Library of Science One, 6(6), ezo101.

BOSF. (2016). Annual report 2015. Borneo Orangutan Survival Foundation. Bogor, Indonesia. Retrieved from http://orangutan.or.id/download/

BOSF. (2017). Annual report 2016. Borneo Orangutan Survival Foundation. Bogor, Indonesia. Retrieved from http://orangutan.or.id/download/

Braverman, I. (2012). Zooland: The institution of captivity. Redwood City, CA: Stanford University Press. 
Brüne, M., Brüne-Cohrs, U., McGrew, W. C., \& Preuschoft, S. (2006). Psychopathology in great apes: Concepts, treatment options and possible homologies to human psychiatric disorders. Neuroscience and Biobehavioral Reviews, 3o(8), 1246-59.

BukitLawang.com. (2017). Information about Bukit Lawang. Retrieved May 16, 2017, from http://www.bukitlawang.com/Info

Bullo, K. (2015). Reaching for the canopy: A zoo-born orangutan's journey into the wild. Crawley, Western Australia: uwa Publishing.

Callicott, J. B. (1980). Animal liberation: A triangular affair. Environmental Ethics, $2(4), 311-38$

Callicott, J. B. (1992). Animal liberation and environmental ethics: Back together again. In E. C. Hargrove (Ed.), The animal rights/environmental ethics debate: The environmental perspective (pp. 249-61). Albany, NY: State University of New York Press.

Cheyne, S. M. (2009). Challenges and opportunities of primate rehabilitation: Gibbons as a case study. Endangered Species Research, 9(2), 159-65.

CITES. (1983). Convention on International Trade in Endangered Species of Wild Fauna and Flora. Retrieved August 20, 2018, from https://cites.org/eng/disc/ text.php

Cocks, L. \& Bullo, K. (2008). The processes for releasing a zoo-bred Sumatran orang-utan Pongo abelii at Bukit Tigapuluh National Park, Jambi, Sumatra. International Zoo Yearbook, 42(1), 183-89.

Cribb, R., Gilbert, H., \& Tiffin, H. (2014). Wild man from Borneo: A cultural history of the orangutan. Honolulu: University of Hawai'i Press.

Dellatore, D. F., Waitt, C. D., \& Foitovà, I. (2014). The impact of tourism on the behavior of rehabilitated orangutans (Pongo abelii) in Bukit Lawang, North Sumatra, Indonesia. In A. E. Russon \& J. Wallis (Eds.), Primate tourism: A tool for conservation? (pp. 98-120). Cambridge: Cambridge University Press.

Doron, H. (2015). Interview with Ashley Leiman - The Orangutan Foundation. 17th April. Helen Doron Radio. Retrieved May 29, 2015, from https://www. youtube.com/watch?v=UKY 3 scPIMd8\&feature=youtube_gdata_player

Elder, M. (2016). 2015 international studbook of the orangutan (Pongo pygmaeus, Pongo abelii). World Association of Zoos and Aquariums, Como Zoo. Saint Paul, Minnesota.

Fam, S., Tan, Y., \& Waitt, C. (2012). Stereotypies in captive primates and the use of inositol: Lessons from obsessive-compulsive disorder in humans. International fournal of Primatology, 33(4), 1-15.

Fisher, L. (2010). Lessons learned report: Orangutan Conservation Services Program. eForest Management Consultants. Jakarta.

Foltz, R. (2014). Animals in Islamic traditions and Muslim cultures. London: Oneworld Publications.

Galdikas, B. M. F. (1995). Reflections of Eden: My years with the orangutans of Borneo. Boston, MA: Little Brown and Company. 
Gipps, J. H. W. (1991). Beyond captive breeding: Re-introducing endangered mammals to the wild: The proceedings of a symposium held at the Zoological Society of London on 24th and 25th November 1989. Oxford: Clarendon Press.

Goodall, J. (2001). Foreword: Problems faced by wild and captive chimpanzees: Finding solutions. In B. B. Beck, T. S. Stoinski, M. Hutchins, T. L. Maple, B. G. Norton, A. N. Rowan, ... A. Arluke (Eds.), Great apes and humans: The ethics of coexistence (pp. xxiii-xxiv). Washington DC: Smithsonian Institution Press.

Greenhough, B. \& Roe, E. (2017). Exploring the role of animal technologists in implementing the 3rs: An ethnographic investigation of the UK university sector. Science, Technology, \& Human Values.

Guy, A. J., Curnoe, D., \& Banks, P. B. (2014). Welfare based primate rehabilitation as a potential conservation strategy: Does it measure up? Primates, 55(1), 139-147.

Harcourt, A. H. (1987). Options for unwanted or confiscated primates. Primate Conservation, $8(1)$.

Hargrove, E. C. (1992). Preface: Animal welfare ethics "versus" environmental ethics: The problem of sentient life. In E. C. Hargrove (Ed.), The animal rights/environmental ethics debate: The environmental perspective (pp. ixxxvi). Albany, NY: State University of New York Press.

Harrington, L. A., Moehrenschlager, A., Gelling, M., Atkinson, R. P. D., Hughes, J., \& Macdonald, D. W. (2013). Conflicting and complementary ethics of animal welfare considerations in reintroductions. Conservation Biology, 27(3), 486500 .

Harrisson, B. (1962). Orang-utan. London: Collins.

Humle, T. \& Farmer, K. H. (2015). Primate rehabilitation in Africa: Myths and realities. Society for Conservation Biology. Retrieved October 28, 2015, from https://conbio.org/groups/sections/africa/act/primate-rehabilitation-inafrica-myths-and-realities

Husson, S. J., Kurniawan, D., Purnomo, P., Boyd, N., Suyoko, A., SunderlandGroves, J., \& Sihite, J. (2016). The survival and adaptation of reintroduced ex-captive orangutans in Central Kalimantan, Indonesia. In 26th Congress of the International Primatological Society and the 39th Meeting of the American Society of Primatologists. Chicago, IL.

IAR. (2013). Annual review 2013: Rescuing and rehabilitating endangered wildlife. Uckfield, UK: International Animal Rescue. Retrieved from https://www. internationalanimalrescue.org/publications

IUCN. (2000). IUCN guidelines for the placement of confiscated animals. IUCN Species Survival Commission. Retrieved from https://portals.iucn.org/library/efiles/ documents/2002-004.pdf

Jamieson, D. (1995). Wild/captive and other suspect dualisms. In A. N. Rowan (Ed.), Wildlife conservation, zoos and animal protection: A strategic analysis (pp. 31-48). Philadelphia, PA: Tufts Center for Animals and Public Policy. 
Karesh, W. B. (1995). Wildlife rehabilitation: Additional considerations for developing countries. Journal of Zoo and Wildlife Medicine, 26(1), 2-9.

Kortlandt, A. (1994). Spirits dressed in furs? In P. Cavalieri \& P. Singer (Eds.), The Great Ape Project: Equality beyond humanity (pp. 137-44). New York: St. Martin's Press.

Kuze, N., Dellatore, D. F., Banes, G. L., Pratje, P., Tajima, T., \& Russon, A. E. (2012). Factors affecting reproduction in rehabilitant female orangutans: Young age at first birth and short inter-birth interval. Primates, 53(2), 181-92.

Lardoux-Gilloux, I. (1995). Rehabilitation centers: Their struggle, their future. In B. M. F. Galdikas, R. D. Nadler, N. Rosen, \& L. K. Sheeran (Eds.), The neglected ape (pp. 61-68). New York: Springer.

Lees, C. M. \& Wilcken, J. (2009). Sustaining the ark: The challenges faced by zoos in maintaining viable populations. International Zoo Yearbook, 43(1), 6-18.

Lindburg, D. G. (1995). Preserving individuals versus conserving populations: Is there a conflict? In A. N. Rowan (Ed.), Wildlife conservation, zoos and animal protection: A strategic analysis (pp. 152-69). Philadelphia, PA: Tufts Center for Animals and Public Policy.

MacKinnon, K. \& MacKinnon, J. (1991). Habitat protection and re-introduction programmes. In J. H. W. Gipps (Ed.), Beyond captive breeding: Re-introducing endangered mammals to the wild: The proceedings of a symposium held at the Zoological Society of London on 24th and 25th November 1989 (pp. 173-98). Oxford: Clarendon Press.

Marvier, M. (2014). New conservation is true conservation. Conservation Biology, $28(1), 1-3$.

McComb, S. (2009). Hair-plucking and hair-loss in captive chimpanzees (Pan troglodytes) (Unpublished BA thesis, University of Cambridge).

Meijaard, E. (2014). Orangutan conservation management in Kalimantan: Recommendations for improving orangutan conservation strategy. People \& Nature Consulting International. Bali.

Meijaard, E. (2015). Who owns Indonesia's protected species? Jakarta Globe, 17th September. Retrieved October 2, 2015, from http://jakartaglobe.id/opinion/ erik-meijaard-owns-indonesias-protected-species/

Meijaard, E. (2017). Orangutan conservation: Government agencies no 'cleaning service'. The fakarta Post, 2oth fuly. Retrieved August 11, 2017, from http: //www. thejakartapost. com/life/2017/07/20/orangutan - conservation government-agencies-no-cleaning-service.html

Moore, R. S., Wihermanto, \& Nekaris, K. A. I. (2014). Compassionate conservation, rehabilitation and translocation of Indonesian slow lorises. Endangered Species Research, 26(2), 93-102.

Morris, P. (2012). Blue juice: Euthanasia in veterinary medicine. Philadelphia, PA: Temple University Press.

Muehlenbein, M. P., Martinez, L. A., Lemke, A. A., Ambu, L., Nathan, S., Alsisto, S., \& Sakong, R. (2010). Unhealthy travelers present challenges to sustainable primate ecotourism. Travel Medicine and Infectious Disease, 8(3), 169-75. 
Neumayr, M. \& Handy, F. (2017). Charitable giving: What influences donors' choice among different causes? VOLUNTAS: International fournal of Voluntary and Nonprofit Organizations, 1-29.

Nijman, V. (2009). An assessment of trade in gibbons and orang-utans in Sumatra, Indonesia. TRAFFIC Southeast Asia. Kuala Lumpur. Retrieved March 3, 2016, from http://awsassets.wwf.es/downloads/traffic_species_mammals47.pdf

Norton, B. G. (1982). Environmental ethics and nonhuman rights. Environmental Ethics, 4(1), 17-36.

Norton, B. G. (1995). A broader look at animal stewardship. In B. G. Norton, M. Hutchins, E. F. Stevens, \& T. L. Maple (Eds.), Ethics on the ark: Zoos, animal welfare, and wildlife conservation (pp. 102-21). Washington: Smithsonian Institution Press.

Nury, D. R. (2011). The effects of tourism on orangutan (Pongo pygmaeus) behaviour in reintroduction sites Camp Leakey and Camp Siswoyo, Central Kalimantan (Master of Forestry thesis, Universitas Gadjah Mada, Yogyakarta).

OAUK. (2016). Two more releases into Tabin Reserve. Orangutan Appeal UK. 27th May. Retrieved June 9, 2016, from https://www.orangutan-appeal.org.uk/ about-us/news/article/two-more-releases-into-tabin

OFI. (2014). OFI annual report. Orangutan Foundation International. Retrieved from https://orangutan.org/about/annual-report/

OFI. (2015). OFI annual report. Orangutan Foundation International. Retrieved from https://orangutan.org/about/annual-report/

Orne, J. \& Bell, M. (2015). An invitation to qualitative fieldwork: A multilogical approach. London: Routledge.

Palmer, A. (2018). Saving and sacrificing: Ethical questions in orangutan rehabilitation ( $\mathrm{PhD}$ thesis in anthropology, University College London).

Palmer, A., Malone, N., \& Park, J. (2016). Caregiver/orangutan relationships at Auckland Zoo: Empathy, friendship, and ethics between species. Society and Animals, 24(3), 230-49.

Paquet, P. C. \& Darimont, C. T. (2010). Wildlife conservation and animal welfare: Two sides of the same coin. Animal Welfare, 19(2), 177-90.

Parreñas, R. S. (2012). Producing affect: Transnational volunteerism in a Malaysian orangutan rehabilitation center. American Ethnologist, 39(4), 673-87.

Perth Zoo. (2016). Perth Zoo orangutan released to the wild. Retrieved March 31, 2017, from https://perthzoo.wa.gov.au/article/perth-zoo-orangutanreleased-wild

Piper, G. \& Schnepf, S. V. (2008). Gender differences in charitable giving in Great Britain. VOLUNTAS: International fournal of Voluntary and Nonprofit Organizations, 19(2), 103-24.

Ramp, D. (2013). Bringing compassion to the ethical dilemma in killing kangaroos for conservation. Journal of Bioethical Inquiry, 10(2), 267-72.

Ramp, D. \& Bekoff, M. (2015). Compassion as a practical and evolved ethic for conservation. BioScience, 65(3), 323-27. 
Regan, T. (1983 [2004]). The case for animal rights (2nd ed.). Berkeley, CA: University of California Press.

Rijksen, H. D. (2001). The orangutan and the conservation battle in Indonesia. In B. B. Beck, T. S. Stoinski, M. Hutchins, T. L. Maple, B. G. Norton, A. N. Rowan, ... A. Arluke (Eds.), Great apes and humans: The ethics of coexistence (pp. 57-70). Washington DC: Smithsonian Institution Press.

Rijksen, H. D. \& Meijaard, E. (1999). Our vanishing relative: The status of wild orangutans at the close of the twentieth century. Dordrecht: Kluwer Academic Publishers.

Rose, A. L. (1995). Orangutans, science, and collective reality. In B. M. F. Galdikas, R. D. Nadler, N. Rosen, \& L. K. Sheeran (Eds.), The neglected ape (pp. 29-40). New York: Springer.

Rouxel, P. (2012). Green: Death of the forests. Al fazeera, 14th March. Retrieved March 29, 2017, from http://www.aljazeera.com/programmes/witness/2012/ 03/201231483446653151.html

Russon, A. E. (2009). Orangutan rehabilitation and reintroduction. In S. A. Wich, S. S. Utami Atmoko, T. Mitra Setia, \& C. P. van Schaik (Eds.), Orangutans: Geographic variation in behavioral ecology and conservation (pp. 327-50). Oxford: Oxford University Press.

Russon, A. E., Smith, J. J., \& Adams, L. (2016). Managing human-orangutan relationships in rehabilitation. In M. T. Waller (Ed.), Ethnoprimatology: Primate conservation in the 21st century (pp. 233-58). New York: Springer.

Russon, A. E. \& Susilo, A. (2014). Orangutan tourism and conservation: 35 years' experience. In A. E. Russon \& J. Wallis (Eds.), Primate tourism: A tool for conservation? (pp. 76-97). Cambridge: Cambridge University Press.

Seal, U. S. (1991). Life after extinction. In Beyond captive breeding: Re-introducing endangered mammals to the wild: The proceedings of a symposium held at the Zoological Society of London on 24th and 25th November 1989 (pp. 39-55). Oxford: Clarendon Press.

Siegel, S. (2005). Reflections on anthropomorphism in "The disenchanted forest". In L. Daston \& G. Mitman (Eds.), Thinking with animals: New perspectives on anthropomorphism (pp. 196-222). New York: Columbia University Press.

Singleton, I. (2011). From the forest: Jantho, Aceh Besar, Sumatra 2011. Orangutan Conservancy, 21st November. Retrieved December 11, 2017, from http://www. orangutan.com/from-the-forest-jantho-aceh-besar-sumatra-2011/

Siregar, R. S. E. (2010). Behavioural assessment of orang-utans during rehabilitation and reintroduction in East Kalimantan, Indonesia $(\mathrm{PhD}$ thesis, University of Cambridge).

Soulé, M. E. (2013). The "new conservation". Conservation Biology, 27(5), 895-97.

Swaisgood, R. R. (2010). The conservation-welfare nexus in reintroduction programmes: A role for sensory ecology. Animal Welfare, 19(2), 125-37.

Teleki, G. (2001). Sanctuaries for ape refugees. In B. B. Beck, T. S. Stoinski, M. Hutchins, T. L. Maple, B. G. Norton, A. N. Rowan, ... A. Arluke (Eds.), Great 
apes and humans: The ethics of coexistence (pp. 133-49). Washington DC: Smithsonian Institution Press.

Tokiomate, D. (2015). Orangutan rescue. Retrieved September 13, 2016, from https: //www.youtube.com/watch?v=oCfMiWbTXEU

TOP. (2016). Freedom is close, the jungle is calling... The Orangutan Project: appeals. Retrieved February 19, 2016, from https://www.orangutan.org.au/donate/ freedom-is-close-the-jungle-is-calling/

Trayford, H. R. (2013). Continuity and change: (re)conceptualising practice in orangutan (Pongo spp.) rehabilitation and reintroduction in Indonesia $(\mathrm{PhD}$ thesis, University of Cambridge).

Trayford, H. R. \& Farmer, K. H. (2012). An assessment of the use of telemetry for primate reintroductions. Fournal for Nature Conservation, 20(6), 311-25.

Trayford, H. R. \& Farmer, K. H. (2013). Putting the spotlight on internally displaced animals (IDAS): A survey of primate sanctuaries in Africa, Asia, and the Americas. American fournal of Primatology, 75(2), 116-34.

Utami Atmoko, S. S., Traylor-Holzer, K., Rifqi, M. A., Siregar, P. G., Achmad, B., Priadjati, A., ... Lees, C. M. (2017). Final report: Orangutan Population and Habitat Viability Assessment. Apple Valley, MN: IUCN/ssc Conservation Breeding Specialist Group.

Vucetich, J. A. \& Nelson, M. P. (2007). What are 60 warblers worth? Killing in the name of conservation. Oikos, 116(8), 1267-78.

Warren, M. A. (1992). The rights of the nonhuman world. In E. C. Hargrove (Ed.), The animal rights/environmental ethics debate: The environmental perspective (pp. 185-210). Albany, NY: State University of New York Press.

Warren, M. A. (2001). The moral status of great apes. In B. B. Beck, T. S. Stoinski, M. Hutchins, T. L. Maple, B. G. Norton, A. N. Rowan, ... A. Arluke (Eds.), Great apes and humans: The ethics of coexistence (pp. 313-28). Washington DC: Smithsonian Institution Press.

Wilson, H. B., Meijaard, E., Venter, O., Ancrenaz, M., \& Possingham, H. P. (2014). Conservation strategies for orangutans: Reintroduction versus habitat preservation and the benefits of sustainably logged forest. PLOS ONE, 9(7), e102174.

wLT. (2011). The red ape debate: The future for the orang-utan. Meeting hosted by the World Land Trust at the Royal Geographical Society, London. Retrieved from https://www.youtube.com/watch? $\mathrm{v}=$ goadwwWlz6w\&list= PL96E 7 E04959EDBEA9

Yeager, C. P. (1997). Orangutan rehabilitation in Tanjung Puting National Park, Indonesia. Conservation Biology, 11(3), 802-05. 